\title{
Communication
}

\section{Chr15q25 Genetic Variant rs16969968 Alters Cell Differentiation in Respiratory Epithelia}

\author{
Zania Diabasana ${ }^{1}$, Jeanne-Marie Perotin ${ }^{1,2}$, Randa Belgacemi ${ }^{1}$, Julien Ancel ${ }^{1,2} \oplus$, Pauline Mulette ${ }^{1,2}$, \\ Claire Launois ${ }^{2}$, Gonzague Delepine ${ }^{1,3}$, Xavier Dubernard ${ }^{4}{ }^{\circledR}$, Jean-Claude Mérol ${ }^{1,4}$, Christophe Ruaux ${ }^{5}$, \\ Philippe Gosset ${ }^{6}{ }^{(}$, Uwe Maskos ${ }^{7}$, Myriam Polette ${ }^{1,8}$, Gaëtan Deslée ${ }^{1,2}$ and Valérian Dormoy ${ }^{1, *}$ (D)
}

1 Inserm UMR-S1250, P3Cell, University of Reims Champagne-Ardenne, SFR CAP-SANTE, 51092 Reims, France; zania.diabasana@inserm.fr (Z.D.); jmperotin-collard@chu-reims.fr (J.-M.P.); randa.belgacemi@lundquist.org (R.B.); jancel@chu-reims.fr (J.A.); pmulette@chu-reims.fr (P.M.); gdelepine@chu-reims.fr (G.D.); jcmerol@chu-reims.fr (J.-C.M.); myriam.polette@univ-reims.fr (M.P.); gdeslee@chu-reims.fr (G.D.)

2 Department of Respiratory Diseases, CHU de Reims, Hôpital Maison Blanche, 51092 Reims, France; claunois@chu-reims.fr

3 Department of Thoracic Surgery, CHU de Reims, Hôpital Maison Blanche, 51092 Reims, France

4 Department of Otorhinolaryngology, CHU de Reims, Hôpital Robert Debré, 51092 Reims, France; xdubernard@chu-reims.fr

check for updates

Citation: Diabasana, Z.; Perotin, J.-M.; Belgacemi, R.; Ancel, J.; Mulette, P.; Launois, C.; Delepine, G.; Dubernard, X.; Mérol, J.-C.; Ruaux, C.; et al. Chr15q25 Genetic Variant rs16969968 Alters Cell Differentiation in Respiratory Epithelia. Int. J. Mol. Sci. 2021, 22, 6657. https://doi.org/10.3390/ ijms22136657

\section{Academic Editors:}

Emanuela Leonardi,

Giovanni Minervini and

Castrense Savojardo

Received: 31 May 2021

Accepted: 17 June 2021

Published: 22 June 2021

Publisher's Note: MDPI stays neutra with regard to jurisdictional claims in published maps and institutional affiliations.

Copyright: (c) 2021 by the authors. Licensee MDPI, Basel, Switzerland. This article is an open access article distributed under the terms and conditions of the Creative Commons Attribution (CC BY) license (https:/ / creativecommons.org/licenses/by/ $4.0 /)$.
5 Department of Otorhinolaryngology, Clinique Mutualiste La Sagesse, 35043 Rennes, France; christophe.ruaux@hospigrandouest.fr

6 CNRS UMR9017, Inserm U1019, University of Lille, Centre Hospitalier Régional Universitaire de Lille Institut Pasteur, CIIL-Center for Infection and Immunity of Lille, 59000 Lille, France; philippe.gosset@pasteur-lille.fr

7 Integrative Neurobiology of Cholinergic Systems, Institut Pasteur, CNRS UMR 3571, 75015 Paris, France; uwe.maskos@pasteur.fr

8 Department of Biopathology, CHU de Reims, Hôpital Maison Blanche, 51092 Reims, France

* Correspondence: valerian.dormoy@univ-reims.fr

Abstract: The gene cluster region, CHRNA3/CHRNA5/CHRNB4, encoding for nicotinic acetylcholine receptor (nAChR) subunits, contains several genetic variants linked to nicotine addiction and brain disorders. The CHRNA5 single-nucleotide polymorphism (SNP) rs16969968 is strongly associated with nicotine dependence and lung diseases. Using immunostaining studies on tissue sections and air-liquid interface airway epithelial cell cultures, in situ hybridisation, transcriptomic and cytokines detection, we analysed rs16969968 contribution to respiratory airway epithelial remodelling and modulation of inflammation. We provide cellular and molecular analyses which support the genetic association of this polymorphism with impaired ciliogenesis and the altered production of inflammatory mediators. This suggests its role in lung disease development.

Keywords: rs16969968; airway epithelial cells; differentiation; remodelling; inflammation

\section{Introduction}

Chronic inflammatory pulmonary diseases are characterized by alterations in lung tissues (e.g., airway remodelling, inflammation, fibrosis) and pulmonary function. Those alterations can be caused by the inhalation of noxious particles, including tobacco smoke. In addition to environmental factors, multiple genetic susceptibilities have been associated with the development of pulmonary diseases [1]. Nonetheless, only alpha1-antitrypsin deficiency provided insights into the pathogenesis of respiratory disorders and helped improve patient management [2]. The CHRNA3/CHRNA5/CHRNB4 gene cluster, encoding for the $\alpha 3, \alpha 5$ and $\beta 4$ nicotinic acetylcholine receptor (nAChR) subunits, has drawn interest due to its implication in nicotine dependence and lung cancer. The activation of $\mathrm{nAChRs}$ by nicotine has been implicated in the modulation of airway epithelial cell (AEC) response and inflammatory reaction [3]. 
The non-synonymous single-nucleotide CHRNA5 polymorphism, rs16969968, has been identified as clinically significant [4-6]. This mutation is located in the chromosomal region $15 \mathrm{q} 25.1$ and, due to a $\mathrm{G}$ to $A$ base change, leading to the amino acid substitution D398N (aspartic acid to asparagine) in the resulting protein [7,8]. Rs16969968, originally identified as a candidate gene associated with smoking [9], is now identified as a candidate gene associated with nicotine dependence [10], schizophrenia [11], and lung cancer [12-14], as well as during chronic obstructive pulmonary disease (COPD) and altered lung functions [15-21]. It was present in approximately $60 \%$ of the population and its frequency significantly increased in lung diseases $[6,9,12-14,16,17]$. Although the expression of the rs16969968 polymorphism ( $\alpha 5 \mathrm{SNP})$ affected nicotine-induced signalling, its effects on lung histomorphological patterns are not established. In this study, we aimed to determine whether $\alpha 5 \mathrm{SNP}$ is involved in AEC differentiation and remodelling in human lung.

\section{Results}

We first confirmed the detection of CHRNA5 expression in bronchial epithelial cells using in situ hybridisation on formalin-fixed paraffin-embedded (FFPE) lung tissues (Supplemental Figure S1) [22]. We next compared epithelial remodelling features on lung tissues obtained from $\alpha 5 \mathrm{WT}$ and $\alpha 5 \mathrm{SNP}$ patients. Epithelial height did not differ between the two groups (Figure 1A,B). The percentage of remodelled epithelium, including goblet cell hyperplasia, basal cell hyperplasia, and metaplasia, as well as the proliferative index, did not show any significant difference between the two groups (Figure 1A-D). Focusing on the main bronchial epithelial cell populations, we observed that the number of multiciliated cells was significantly decreased in $\alpha 5 \mathrm{SNP}$ patients compared to $\alpha 5 \mathrm{WT}$ patients (247.4 \pm 15.93 ciliated cells $/ \mathrm{mm}$ vs. $186.9 \pm 8.67$ ciliated cells $/ \mathrm{mm}, p<0.01)$ (Figure 1C,D). There was no difference in the number of basal cells or secretory cells (Muc5ac-, Muc5b-, and Uteroglobin-secreting cells) between the two groups.

To dissect the role of rs16969968 during differentiation, we performed a kinetic analysis of AEC cultured in ALI conditions for 35 days. Transepithelial electrical resistance was significantly higher in $\alpha 5 \mathrm{SNP}$ compared to the $\alpha 5 \mathrm{WT}$ group, as observed at ALI35 $\left(325.1 \pm 16.98 \Omega / \mathrm{cm}^{2}\right.$ vs. $\left.169.3 \pm 17.55 \Omega / \mathrm{cm}^{2}, p<0.01\right)$ (Figure $\left.2 \mathrm{~A}\right)$. Focusing on multiciliated, basal, and mucin-secreting cells, we performed comparative quantitative transcriptomic and localization analyses during AEC differentiation. Transcript analyses at ALI-7, ALI-14, and ALI-35 demonstrated a significant decrease of 40 to $85 \%$ in FOXJ1, CK5, MUC5AC, and MUC5B gene expressions in $\alpha 5$ SNP compared to $\alpha 5 \mathrm{WT}$ cells (Figure 2B). a5SNP-ALI cultures had fewer multiciliated cells at ALI-14 (3694 \pm 294.0 mean grey value (MGV) in $\alpha 5 \mathrm{WT}$ vs. $2681 \pm 302.6 \mathrm{MGV}$ in $\alpha 5 \mathrm{SNP}$-expressing cells, $p<0.05$ ) and this pattern was maintained at the end of differentiation, although the difference was not significant (11160 $\pm 1081 \mathrm{MGV}$ in $\alpha 5 \mathrm{WT}$ vs. $9641 \pm 620.8 \mathrm{MGV}$ in $\alpha 5$ SNP-expressing cells, $p=0.21$ ) (Figure 2C,D). $\alpha 5$ SNP-ALI cultures had more basal cells at ALI35 (2950 $\pm 752.6 \mathrm{MGV}$ in $\alpha 5 \mathrm{WT}$ vs. $4672 \pm 526.6 \mathrm{MGV}$ in $\alpha 5 \mathrm{SNP}$-expressing cells) but did not reach statistical significance (Figure 2C,D). The number of mucin-secreting cells did not significantly differ between the two groups (Figure 2C,D). 
A
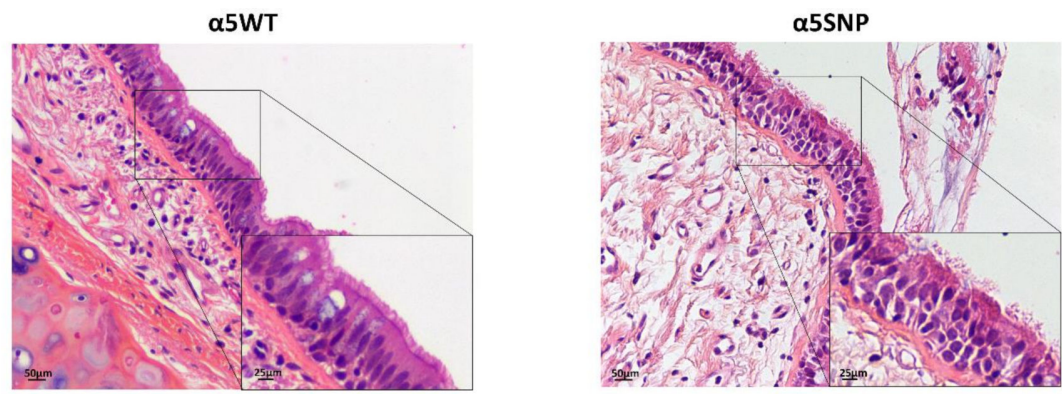

B

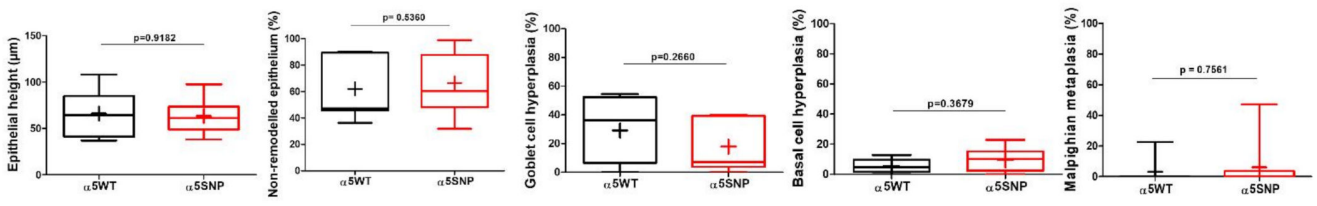

C

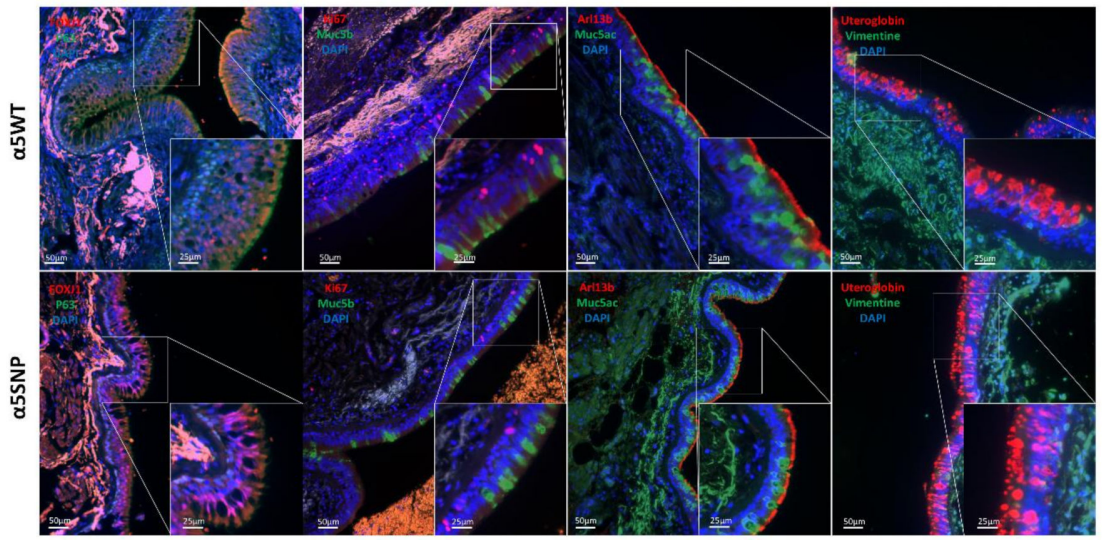

D

Proliferation
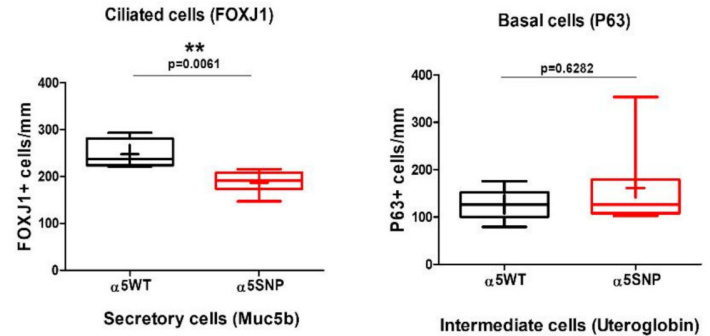

Secretory cells (Muc5ac)
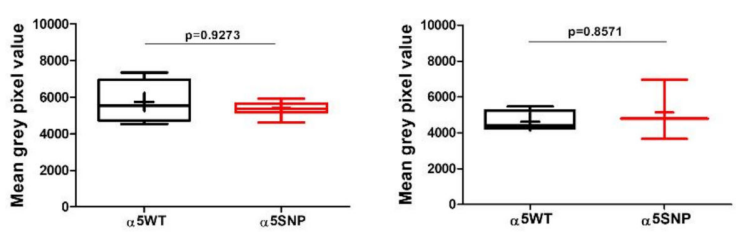

Intermediate cells (Uteroglobin)

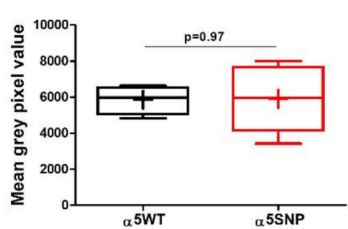

Figure 1. SNP rs16969968 is associated with a decrease in multiciliated cells in bronchi epithelia. (A) Representative micrographs showing the bronchial epithelia of $\alpha 5 \mathrm{WT}$ - and $\alpha 5 \mathrm{SNP}$-expressing patients stained for haematoxylin and eosin. Magnification corresponding to the selected area is shown. (B) Box and whisker plots (median with min to max, the plus sign (+) represents the mean value) represent the measurements of epithelium height $(\mu \mathrm{m})$, and the percentage of non-remodelled and remodelled (basal cell hyperplasia, goblet cell hyperplasia and metaplasia) epithelium in $\alpha 5 \mathrm{WT}$ (black) and $\alpha 5$ SNP-expressing (red) groups ( $\mathrm{n} \geq 7$ for each group). (C) Representative micrographs showing the bronchial epithelia of $\alpha 5 \mathrm{WT}$ and $\alpha 5 \mathrm{SNP}$-expressing patients stained for ciliated cells (Arl13b and FOXJ1, red), intermediate cells (uteroglobin, red), proliferative cells (Ki67, red), basal cells (P63, green), mucin-secreting cells (Muc5ac and Muc5b, green), intermediate filaments (vimentin, green) and cell nuclei (DAPI, blue). Magnification corresponding to the selected area is shown. (D) Box and whisker plots (median with min to max, the plus sign (+) represents the mean value) report the proportion of FOXJ1and P63-positive cells per $\mathrm{mm}$, the proliferative index, and the mean grey pixel values of mucin- and uteroglobin-associated fluorescence in $\alpha 5 \mathrm{WT}$ (black) and $\alpha 5 \mathrm{SNP}$-expressing cells (red) ( $\mathrm{n} \geq 3$ for each group). ${ }^{* *} p<0.01 \alpha 5 \mathrm{WT}$ vs. $\alpha 5 \mathrm{SNP}$. 
A

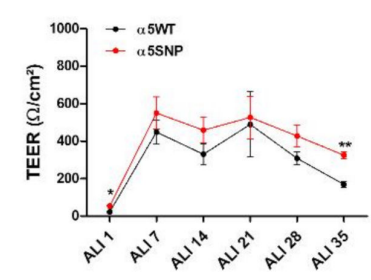

B

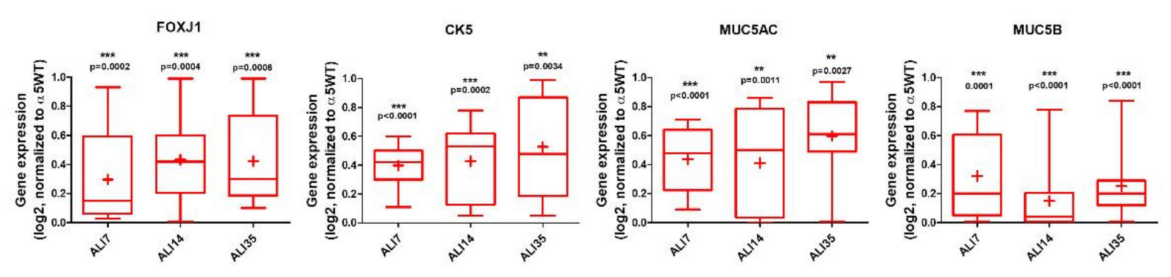

C
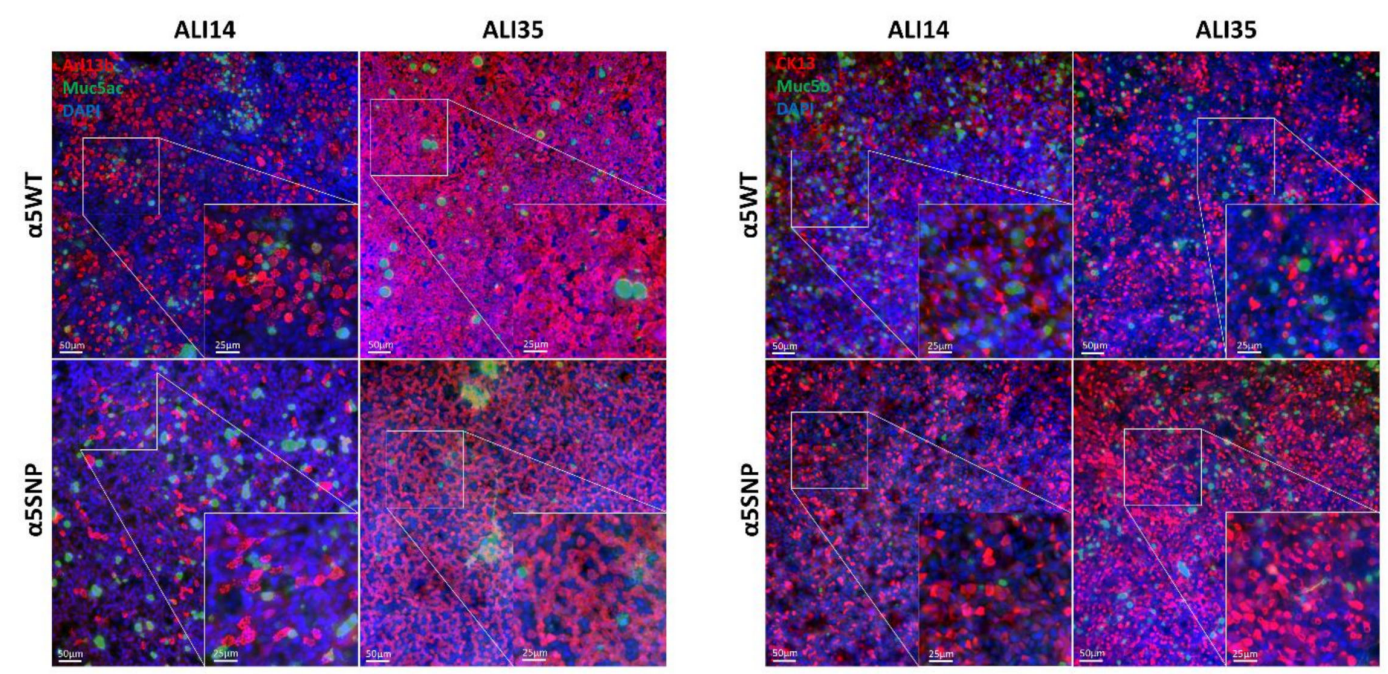

D
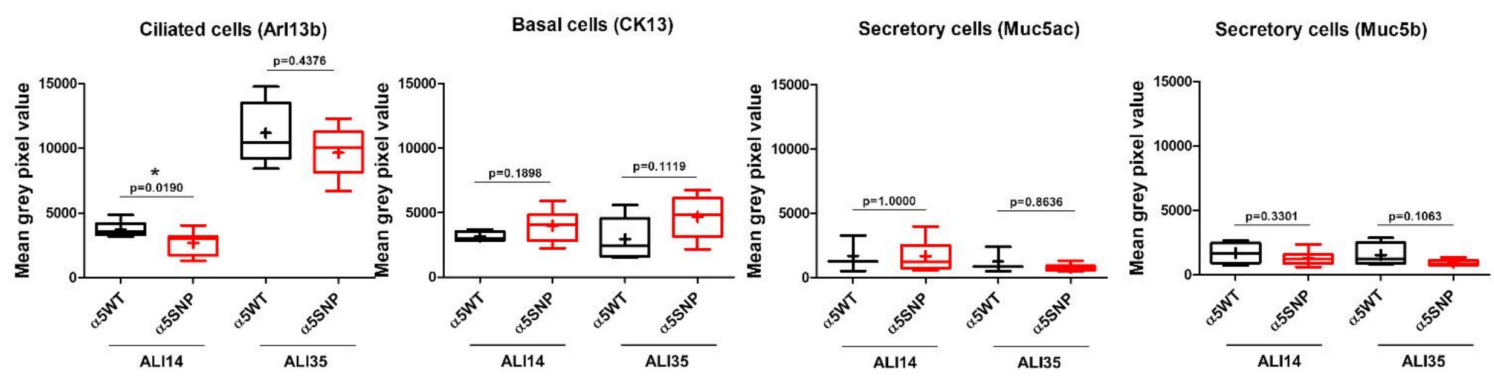

Figure 2. SNP rs16969968 alters respiratory airway epithelial cell differentiation. (A) Curves represent the TEER of AEC ( $n=13)$ measured at ALI-1, ALI-7, ALI-14, ALI-21, ALI-28, and ALI-35 in $\alpha 5 \mathrm{WT}$ (black) and $\alpha 5$ SNP-expressing (red) cells. Means \pm SEM are shown for each ALI time point. ${ }^{*} p<0.05$; ${ }^{* * *} p<0.001 \alpha 5 \mathrm{WT}$ vs. $\alpha 5 \mathrm{SNP}$. (B) Box and whisker plots (median with min to max, the plus sign (+) represents the mean value) represent the relative mRNA levels during ALI cultures by RT-qPCR $(n=13)$ for differentiation markers (CK5, non-differentiated cells; FOXJ1, ciliated cells; MUC5AC/MUC5B, mucous-secreting cells) in $\alpha 5$ SNP-expressing groups. ${ }^{*} p<0.05 ;{ }^{* *} p<0.01$; ${ }^{* * *} p<0.001 \alpha 5 \mathrm{WT}$ vs. $\alpha 5$ SNP. (C) Examples of micrographs taken from AEC cultures at ALI-14 and ALI-35 showing multiciliated (Arl13b, red) and mucin-secreting (Muc5ac, green) cells on the left, basal (CK13, red) and mucin-secreting (Muc5b, green) cells on the right. Nuclei are stained in blue (DAPI). Magnification corresponding to the selected area is shown. (D) Box and whisker plots (median with min to max, the plus sign (+) represents the mean value) represent the mean grey pixel values of Arl13b-, CK13-, muc5ac- and muc5b-associated fluorescence at ALI-14 and ALI-35 in $\alpha 5 \mathrm{WT}$ (black) and $\alpha 5$ SNP-expressing cells (red) (n $\geq 3$ for each group). ${ }^{*} p<0.05 \alpha 5 \mathrm{WT}$ vs. $\alpha 5 \mathrm{SNP}$.

We next analysed the expression of inflammatory mediators in apical and basal cell culture supernatants (Figure 3 and Supplemental Figure S2). On average, there was a significant two-fold decrease in pro- and anti-inflammatory protein expression in $\alpha 5 \mathrm{SNP}$-expressing cells compared to $\alpha 5 \mathrm{WT}$, including GR $0 \alpha$, sICAM- 1 , IFN $\gamma$, IL-2/5/6/10/12p70/32 $\alpha$, IP-10, MCP-1, MIF, RANTES, and SDF-1. In addition, IL-17/17E $/ 1 \mathrm{ra} / 1 \alpha / 1 \beta / 4$, and MIP- $1 \alpha$ were also detected but the ratios did not statistically differ. The ratios were consistent for both secretory compartments. 


\begin{tabular}{|c|c|c|c|c|c|c|c|c|c|c|c|c|}
\hline Color Key & \multicolumn{6}{|c|}{ Apical side } & \multicolumn{6}{|c|}{ Basal side } \\
\hline$-<0.25$ & MIP-1 $\alpha$ & IL-17E & sICAM-1 & IL-4 & IL-10** & IL-17 & MIP-1 $\alpha$ & IL-17E & sICAM-1** & IL-4 & IL-10 & IL-17 \\
\hline $\begin{array}{r}-0.25-0.5 \\
-0.5-0.75\end{array}$ & SDF-1*** & RANTES*** & IL-1 $\beta$ & IL-1 $\alpha$ & $\mathrm{GRO} \alpha^{*}$ & IL-5*** & SDF-1*** & RANTES & $\mathrm{IL}-1 \beta$ & $\mathrm{IL}-1 \alpha$ & $\mathrm{GRO} \alpha * * *$ & IL-5* \\
\hline$-0.75-1$ & IL-1ra & IP-10*** & IL-12 p $70 * *$ & MIF** & IL-32a*** & IL-6*** & IL-1ra & IP-10** & IL-12 p70* & MIF*** & $\mathrm{IL}-32^{\alpha * *}$ & $\mathrm{IL}-6^{* * *}$ \\
\hline $\begin{array}{l}-1-1.25 \\
-1.25-1.5\end{array}$ & MCP-1*** & $\mathrm{IL}-2^{* * *}$ & IFN- $\gamma^{* * *}$ & $\mathrm{C} 5 / \mathrm{C} 5 \mathrm{a}$ & CD40 Ligand & G-CSF & MCP-1*** & $\mathrm{IL}-2^{* * *}$ & IFN- $\gamma^{*}$ & $\mathrm{C} 5 / \mathrm{C} 5 \mathrm{a}$ & CD40 Ligand & G-CSF \\
\hline & $\mathrm{IL}-27$ & I-TAC & MIP-1 $\beta$ & Serpin E1 & TNF- $\alpha$ & STREM-1 & IL-27 & I-TAC & MIP-1 $1 \beta$ & Serpin E1 & TNF- $\alpha$ & sTREM-1 \\
\hline
\end{tabular}

Figure 3. Cytokine and chemokine expression in AEC culture supernatants. Heat map colours correspond to the $\alpha 5 \mathrm{SNP} / \alpha 5 \mathrm{WT}$ cytokine and chemokine ratios at ALI-7 from apical (left) and basal (right) supernatants obtained from AEC cultures ( $n=4 \alpha 5 \mathrm{WT}$ and $n=9 \alpha 5 \mathrm{SNP}$ ). Downregulated (blue) and upregulated (orange) proteins in supernatants from $\alpha 5 S N P$-expressing cells are represented. Non-detected proteins are represented in white. ${ }^{*} p<0.05 ;{ }^{* *} p<0.01 ;^{* * *} p<0.001$ $\alpha 5 \mathrm{WT}$ vs. $\alpha 5 \mathrm{SNP}$.

\section{Discussion}

Our data provide experimental clues on AEC to fill the knowledge gap in our understanding of the rs16969968 polymorphism and its genetic association with lung diseases [16]. We demonstrated that $\alpha 5 \mathrm{SNP}$ expression was associated with structural and functional alterations of airway epithelium. One of the most important findings is the $\alpha 5 \mathrm{SNP}$-associated alteration of ciliogenesis, which we observed in both bronchial epithelia and AEC ALI cultures. Cell differentiation was deregulated, as evidenced by transcript levels of ciliated, basal, and mucin-secreting cells. In addition, basal cell cytokine production was reduced, suggesting a global impairment of the epithelial contribution to the inflammatory response during epithelial cell differentiation.

We focused here on the respiratory epithelium from patients with no chronic inflammatory pulmonary disease to investigate the impact of rs16969968 as a forerunner of pulmonary dysregulation. Expanding the experimental approaches to small airways and lung diseases will allow us to fully decipher the role of rs16969968 polymorphism susceptibility in lung histological features [23]. Furthermore, besides epithelial cells, the recruitment of inflammatory cell populations and their cytokine profiles should also be evaluated in $\alpha 5 \mathrm{SNP}$ patients at baseline and in response to an inflammatory stimulus.

Although rs16969968 was identified and associated with several major diseases more than a decade ago, very few molecular studies tackled the biological relevance of this genetic alteration. It has been only demonstrated that $n A C h R s$ containing rs16969968- $\alpha 5$ subunit exhibited an altered response to agonists and calcium permeability [24-26]. Considering the increase in the number of studies reporting its significant genetic association, the molecular and cellular dissection of rs16969968-associated pathogenic mechanisms is paramount.

In conclusion, using a combination of in vitro and ex vivo approaches, we have obtained compelling evidence in support of rs16969968, directly inducing molecular and cellular changes in AEC, ultimately leading to the remodelling and the impairment of the epithelial-related immune response of the airways.

\section{Materials and Methods}

\subsection{Human Subjects}

Patients scheduled for lung resection for cancer (University Hospital of Reims, Reims, France) were prospectively recruited $(n=16)$ following the standards established and approved by the institutional review board of the University Hospital of Reims, France (IRB Reims-CHU, approval date: 2011/06/12). Informed consent was obtained from all the patients. Patients with chronic obstructive pulmonary disease, asthma, cystic fibrosis, bronchiectasis, or pulmonary fibrosis were excluded. At inclusion, age, sex, smoking history, and pulmonary function test results were recorded. 


\subsection{Human Primary Airway Epithelial Cell Cultures}

Human primary airway epithelial cells (AEC) were obtained from nasal polyps resected from non-COPD patients (13 donors) to establish air-liquid interface (ALI) cultures, as described by us and others [27-32]. Cells were dissociated by overnight pronase incubation $(0.5 \mathrm{mg} / \mathrm{mL}$, Sigma-Aldrich, Saint Quentin Falavier, France) and counted with ADAM (NanoEnTek, VWR, Fontenay-sous-Bois, France) according to NanoEnTek instructions. In total, 200,000 cells were seeded on 12-well plates containing $0.4 \mu \mathrm{m}$ Transwells (Corning, Fisher Scientific, Illkirch, France) coated with $0.3 \mathrm{mg} / \mathrm{mL}$ collagen type IV from the human placenta (Sigma-Aldrich, Saint Quentin Falavier, France). PneumaCult-EX (PnC-Ex) media (StemCell, Saint-Egrève, France) were used for initial proliferation in apical and basal chambers. Upon reaching cell confluency, the apical medium was removed, and PneumaCult-ALI (PnC-ALI, StemCell, Saint-Egrève, France) medium was used in the basal chamber. The culture medium was changed three times a week and cells were kept in incubators at $37^{\circ} \mathrm{C}, 5 \% \mathrm{CO} 2$. Cells and supernatants were collected every 7 days to generate kinetic analysis. Cell morphological changes were evaluated weekly under a microscope.

\subsection{TEER Measurements}

Transepithelial electrical resistance (TEER) was evaluated every 7 days using an EVOM2 resistance meter with an STX2 electrode (World Precision Instruments Ltd, Hitchin, UK) at room temperature. The electrode was equilibrated in PnC-ALI for $1 \mathrm{~h}$ at room temperature before measurement. One $\mathrm{mL}$ PnC-ALI was added to the apical compartment and triplicate measurements were performed per sample. Data were corrected for blank values and area. Average resistance was subtracted from the measured value of every well according to data acquired on cell-free permeable supports and results are presented as resistance per surface $\left(\Omega \cdot \mathrm{cm}^{2}\right)$.

\subsection{RT-qPCR Analyses}

Total RNA from AEC was isolated by High Pure RNA isolation kit (Roche Diagnostics, Meylan, France) and 250 ng was reverse transcribed into cDNA by Transcriptor First Stand cDNA Synthesis kit (Roche Diagnostics, Meylan, France). Quantitative PCR reactions were performed with the fast start universal probe master kit and UPLprobe system in a LightCycler 480 Instrument (Roche Diagnostics, Meylan, France) as recommended by the manufacturer. Primers used are listed in Supplemental Table S1. Results for all expression data regarding transcripts were normalized to the expression of the house-keeping gene, GAPDH, amplified with the following primers: forward $5^{\prime}$ ACCAGGTGGTCTCCTCTGAC-3' ${ }^{\prime}$, reverse $5^{\prime}$-TGCTGTAGCCAAATTCGTTG- ${ }^{\prime}$. Relative gene expression was assessed by the $\Delta \Delta \mathrm{Ct}$ method and expressed as $2-\Delta \Delta \mathrm{Ct}$. The transcript levels of $\alpha 5 \mathrm{WT}$ mRNAs were normalized at 1.00 and the transcript levels of SNP mRNAs were comparatively assessed for each gene and at each time-point.

\subsection{DNA Extraction}

Epithelial cell pellets obtained from dissociated human polyps (GenElute ${ }^{\mathrm{TM}}$ RNA/ DNA/Protein Plus Purification Kit, Sigma-Aldrich, Saint Quentin Falavier, France) or four tissue sections (20 $\mu \mathrm{m}$ of thickness each) trimmed from formalin-fixed paraffin-embedded (FFPE) lung tissue blocks (GenElute ${ }^{\mathrm{TM}}$ FFPE RNA/DNA Purification Plus Kit) were processed for DNA purification according to the manufacturer's instructions.

\subsection{Genotyping}

nAChR $\alpha 5$ subunit coding gene, CHRNA5, was amplified with DNA polymerase TaKaRa LA Taq (TAKARA Bio Europe SAS, Saint-Germain-en-Laye, France) using the following primers: forward 5' - AGTCATGTAGACAGGTACTTCACTCAG-3' ${ }^{\prime}$, reverse $5^{\prime}$ TGGAAGAAGATCTGCATTTG-3'. Amplification products were digested with Taq1 enzyme recognizing the following sequence: $5^{\prime}$-TCGA- $3^{\prime}$, only present in the $\alpha 5 \mathrm{WT}$ sequence. 
Digestion products were then separated by agarose gel electrophoresis and gels were imaged using a LAS-1000 Imager for analysis (Aïda software, Raytest, Courbevoie, France).

\subsection{Immunohistochemistry (IHC) and Immunofluorescent (IF) Staining}

Immunohistochemistry and immunofluorescent staining were performed on FFPE lung tissues distant from the tumour, as previously described [33]. Then, $5 \mu \mathrm{m}$ sections were processed for hematoxylin and eosin staining and analysed on a microscope (x20) to assess epithelium height and bronchial epithelium remodelling. FFPE lung tissue section slides were deparaffinized and blocked with 10\% BSA in PBS for 30 min at room temperature. Tissue sections were then incubated with the primary antibodies, as listed in Supplemental Table S2 for one night at $4{ }^{\circ} \mathrm{C}$ in $3 \%$ BSA in PBS. After PBS wash, a second primary antibody was used for $2 \mathrm{~h}$ at room temperature to highlight non-differentiated cells, secretory cells, and intermediate filaments on epithelia: p63 (AF1916, R\&D Systems, Bio-Techne SAS, Noyal Châtillon sur Seiche, France), Muc5ac (NBP2-15196, Novus Biological, Bio-Techne SAS, Noyal Châtillon sur Seiche, France), Muc5b (E-AB-15988, ElabScience, CliniSciences SAS, Nanterre, France), and Vimentin (M0725, Agilent Dako, Les Ulis, France). Sections were washed with PBS and incubated with the appropriate secondary antibodies in 3\% BSA in PBS for $30 \mathrm{~min}$ at room temperature. DNA was stained with DAPI during incubation with the secondary antibodies. Micrographs were acquired on a Zeiss AxioImageur (x20 Ph) with ZEN software $(8.1,2012)$ and processed with ImageJ (National Institutes of Health) for analysis. For each patient, five random fields per section containing bronchi were taken to quantify cell proliferation, differentiated and non-differentiated cell expression, and mucus secretion on the bronchial epithelium. For each field, a threshold was established by subtracting the background with a rolling ball radius of 50.0 pixels setting the minimum at 0 .

\subsection{Whole-Mount Immunofluorescent Immunostaining (WMIF)}

Methanol-fixed AEC from ALI cultures were rehydrated by decreasing methanol concentration before post-fixation with acetone. Cells were then blocked with 10\% BSA in PBS for $2 \mathrm{~h}$ at room temperature and incubated for one night at $4{ }^{\circ} \mathrm{C}$ in $3 \%$ PBS/BSA in PBS with the primary antibodies as listed in Supplementary Table S2. Cells were washed with PBS and incubated with the appropriate secondary antibodies in PBS for $2 \mathrm{~h}$ at room temperature. DNA was stained with DAPI during incubation with the secondary antibodies. Clarification of cells was achieved by a glycerol gradient $(25 \% / 50 \% / 75 \%)$ before mounting the slides. Micrographs were acquired on a Zeiss AxioImageur (x $20 \mathrm{Ph})$ with ZEN software (version 8.1, Zeiss, Marly le Roi, France) and processed with ImageJ, as previously described [34].

\subsection{In Situ Hybridisation}

In situ hybridisation was performed on FFPE lung tissue sections to assess CHRNA5 mRNA expression. Tissue sections were deparaffinized and pretreated with hydrogen peroxide. Target retrieval was then carried out in a steamer for $15 \mathrm{~min}$ and slides were dried overnight at room temperature. After protease pre-treatment, tissue sections were incubated with a CHRNA5 probe for $2 \mathrm{~h}$ at $40^{\circ} \mathrm{C}$. Target amplification was then achieved by successive hybridizations and the signal was detected using DAB substrates. The slides were counterstained using hematoxylin and dehydrated by alcohol and xylene baths before mounting. Micrographs were acquired on a Nikon Eclipse with NIS-Elements software and processed with ImageJ.

\subsection{Immunoblot Analyses}

Thirty-six human cytokines and chemokines expression in apical and basal chamber supernatants $(500 \mu \mathrm{L})$ were assayed by proteome profiler array according to the $\mathrm{R} \& \mathrm{D}$ systems instructions (ARY005B). Final detection was obtained by streptavidin-HRP and 
chemiluminescence. Membranes were then imaged using ImageQuantTM LAS-4000 (GE Healthcare) for analyses. Detected signals were digitally quantified using ImageJ. The values were normalized to the positive and negative controls for each membrane and the proteins were considered detected if their mean maximum grey pixel value of detection exceeded the mean maximum grey pixel value of the negative controls by $5 \%$.

\subsection{Statistics}

The data are expressed as mean values and percentages. A non-parametric MannWhitney test was used to analyse differences between groups or the one-sample t-test to the hypothetical value of 1.00 representing $\alpha 5 W T$ subjects. A $p$-value $<0.05$ was considered significant.

Supplementary Materials: The following are available online at https://www.mdpi.com/article/ 10.3390/ijms22136657/s1, Figure S1: CHRNA5 gene is expressed in the human airways, Figure S2: Cytokine expression at an early stage of differentiation, Table S1: List of primers, Table S2: List of antibodies.

Author Contributions: Conceptualization, V.D.; methodology, Z.D., J.-M.P., P.G., U.M., M.P., G.D. (Gaëtan Deslée), and V.D.; formal analysis, Z.D., J.-M.P., P.G., U.M., M.P., G.D. (Gaëtan Deslée), and V.D.; investigation, Z.D., J.-M.P., R.B., M.P., G.D. (Gaëtan Deslée), and V.D.; resources, J.-M.P., J.A., P.M., C.L., G.D. (Gonzague Delepine), X.D., J.-C.M., C.R., and G.D. (Gaëtan Deslée); data curation, J.-M.P., M.P., G.D. (Gaëtan Deslée), and V.D.; writing-original draft preparation, Z.D., and V.D.; writing—review and editing, Z.D., J.-M.P., P.G., U.M., M.P., G.D. (Gaëtan Deslée), and V.D.; supervision, G.D. (Gaëtan Deslée), and V.D.; project administration, P.G., U.M., M.P., G.D. (Gaëtan Deslée), and V.D.; funding acquisition, P.G., U.M., M.P., G.D. (Gaëtan Deslée), and V.D. All authors have read and agreed to the published version of the manuscript.

Funding: This work was supported by Funding from University of Reims Champagne-Ardenne (Université de Reims Champagne-Ardenne, URCA), the French National Institute of Health and Medical Research (Institut National de la Santé et de la Recherche Médicale, Inserm) and a grant from the Research Institute in Public Health (IReSP) in association with the National Institute of Cancer (INCa). It was carried out in the framework of the Federative Research Structure CAPSanté and benefited from the Project Research and Innovation in Inflammatory Respiratory Diseases (RINNOPARI).

Institutional Review Board Statement: Subjects were recruited from the Department of pulmonary medicine at university hospital of Reims (France) and included in the cohort for Research and Innovation in Chronic Inflammatory Respiratory Diseases (RINNOPARI, NCT02924818). The study was approved by the ethics committee for the protection of human beings involved in biomedical research (CCP Dijon EST I, N ${ }^{\circ}$ 2016-A00242-49) and was conducted in accordance with the ethical guidelines of the Declaration of Helsinki.

Informed Consent Statement: Informed consent was obtained from all subjects involved in the study.

Data Availability Statement: The data presented in this study are available on request from the corresponding author.

Acknowledgments: We thank the members of the Inserm UMR-S 1250 unit and our collaborators for their helpful comments and insights. We thank the Platform of Cell and Tissue Imaging (PICT) for technical assistance.

Conflicts of Interest: Ruaux reports grants and personal fees from Sanofi-Aventis outside the submitted work. Deslée reports personal fees from Nuvaira, personal fees from BTG/PneumRx, personal fees from Chiesi, personal fees from Boehringer, personal fees from Astra Zeneca, outside the submitted work. Dormoy reports personal fees from Chiesi outside the submitted work. The funders had no role in the design of the study; in the collection, analyses, or interpretation of data; in the writing of the manuscript, or in the decision to publish the results. 


$\begin{array}{ll}\text { Abbreviations } \\ \text { AEC } & \text { Airway epithelial cell } \\ \text { COPD } & \text { Chronic obstructive pulmonary disease } \\ \text { FFPE } & \text { Formalin-fixed paraffin-embedded } \\ \text { nAChR } & \text { Nicotinic acetylcholine receptor } \\ \text { SNP } & \text { Single-nucleotide polymorphism } \\ \text { TEER } & \text { Transepithelial electrical resistance }\end{array}$

\section{References}

1. Gaffney, A.; Christiani, D. Gene-Environment Interaction from International Cohorts: Impact on Development and Evolution of Occupational and Environmental Lung and Airway Disease. Semin. Respir. Crit. Care Med. 2015, 36, 347-357. [CrossRef] [PubMed]

2. Strnad, P.; McElvaney, N.G.; Lomas, D.A. Alpha ${ }_{1}$-Antitrypsin Deficiency. N. Engl. J. Med. 2020, 382, 1443-1455. [CrossRef] [PubMed]

3. Lam, D.C.-L.; Luo, S.Y.; Fu, K.-H.; Lui, M.M.-S.; Chan, K.-H.; Wistuba, I.I.; Gao, B.; Tsao, S.-W.; Ip, M.S.-M.; Minna, J.D. Nicotinic Acetylcholine Receptor Expression in Human Airway Correlates with Lung Function. Am. J. Physiol. Lung Cell. Mol. Physiol. 2016, 310, L232-L239. [CrossRef] [PubMed]

4. Cho, M.H.; McDonald, M.-L.N.; Zhou, X.; Mattheisen, M.; Castaldi, P.J.; Hersh, C.P.; DeMeo, D.L.; Sylvia, J.S.; Ziniti, J.; Laird, N.M.; et al. Risk Loci for Chronic Obstructive Pulmonary Disease: A Genome-Wide Association Study and Meta-Analysis. Lancet Respir. Med. 2014, 2, 214-225. [CrossRef]

5. SpiroMeta Consortium; International COPD Genetics Consortium; Sakornsakolpat, P.; Prokopenko, D.; Lamontagne, M.; Reeve, N.F.; Guyatt, A.L.; Jackson, V.E.; Shrine, N.; Qiao, D.; et al. Genetic Landscape of Chronic Obstructive Pulmonary Disease Identifies Heterogeneous Cell-Type and Phenotype Associations. Nat. Genet. 2019, 51, 494-505. [CrossRef]

6. Saccone, N.L.; Culverhouse, R.C.; Schwantes-An, T.-H.; Cannon, D.S.; Chen, X.; Cichon, S.; Giegling, I.; Han, S.; Han, Y.; Keskitalo-Vuokko, K.; et al. Multiple Independent Loci at Chromosome 15q25.1 Affect Smoking Quantity: A Meta-Analysis and Comparison with Lung Cancer and COPD. PLoS Genet. 2010, 6, e1001053. [CrossRef]

7. Weiss, R.B.; Baker, T.B.; Cannon, D.S.; von Niederhausern, A.; Dunn, D.M.; Matsunami, N.; Singh, N.A.; Baird, L.; Coon, H.; McMahon, W.M.; et al. A Candidate Gene Approach Identifies the CHRNA5-A3-B4 Region as a Risk Factor for Age-Dependent Nicotine Addiction. PLoS Genet. 2008, 4, e1000125. [CrossRef]

8. Maskos, U. The Nicotinic Receptor Alpha5 Coding Polymorphism Rs16969968 as a Major Target in Disease: Functional Dissection and Remaining Challenges. J. Neurochem. 2020. [CrossRef]

9. Saccone, S.F.; Hinrichs, A.L.; Saccone, N.L.; Chase, G.A.; Konvicka, K.; Madden, P.A.F.; Breslau, N.; Johnson, E.O.; Hatsukami, D.; Pomerleau, O.; et al. Cholinergic Nicotinic Receptor Genes Implicated in a Nicotine Dependence Association Study Targeting 348 Candidate Genes with 3713 SNPs. Hum. Mol. Genet. 2007, 16, 36-49. [CrossRef]

10. Furberg, H.; Kim, Y.; Dackor, J.; Boerwinkle, E.; Franceschini, N.; Ardissino, D.; Tobacco and Genetics Consortium. The Tobacco and Genetics Consortium Genome-Wide Meta-Analyses Identify Multiple Loci Associated with Smoking Behavior. Nat. Genet. 2010, 42, 441-447. [CrossRef]

11. Schizophrenia Working Group of the Psychiatric Genomics Consortium. Biological Insights from 108 Schizophrenia-Associated Genetic Loci. Nature 2014, 511, 421-427. [CrossRef]

12. Amos, C.I.; Wu, X.; Broderick, P.; Gorlov, I.P.; Gu, J.; Eisen, T.; Dong, Q.; Zhang, Q.; Gu, X.; Vijayakrishnan, J.; et al. Genome-Wide Association Scan of Tag SNPs Identifies a Susceptibility Locus for Lung Cancer at 15q25.1. Nat. Genet. 2008, 40, 616-622. [CrossRef]

13. Hung, R.J.; McKay, J.D.; Gaborieau, V.; Boffetta, P.; Hashibe, M.; Zaridze, D.; Mukeria, A.; Szeszenia-Dabrowska, N.; Lissowska, J.; Rudnai, P.; et al. A Susceptibility Locus for Lung Cancer Maps to Nicotinic Acetylcholine Receptor Subunit Genes on 15q25. Nature 2008, 452, 633-637. [CrossRef]

14. Thorgeirsson, T.E.; Geller, F.; Sulem, P.; Rafnar, T.; Wiste, A.; Magnusson, K.P.; Manolescu, A.; Thorleifsson, G.; Stefansson, H.; Ingason, A.; et al. A Variant Associated with Nicotine Dependence, Lung Cancer and Peripheral Arterial Disease. Nature 2008, 452, 638-642. [CrossRef]

15. Xu, Z.-W.; Wang, G.-N.; Dong, Z.-Z.; Li, T.-H.; Cao, C.; Jin, Y.-H. CHRNA5 Rs16969968 Polymorphism Association with Risk of Lung Cancer-Evidence from 17,962 Lung Cancer Cases and 77,216 Control Subjects. Asian Pac. J. Cancer Prev. 2015, 16, 6685-6690. [CrossRef]

16. Hopkins, R.J.; Duan, F.; Gamble, G.D.; Chiles, C.; Cavadino, A.; Billings, P.; Aberle, D.; Young, R.P. Chr15q25 Genetic Variant (Rs16969968) Independently Confers Risk of Lung Cancer, COPD and Smoking Intensity in a Prospective Study of High-Risk Smokers. Thorax 2021, 76, 272-280. [CrossRef]

17. Pillai, S.G.; Ge, D.; Zhu, G.; Kong, X.; Shianna, K.V.; Need, A.C.; Feng, S.; Hersh, C.P.; Bakke, P.; Gulsvik, A.; et al. A Genome-Wide Association Study in Chronic Obstructive Pulmonary Disease (COPD): Identification of Two Major Susceptibility Loci. PLoS Genet. 2009, 5, e1000421. [CrossRef] 
18. Pillai, S.G.; Kong, X.; Edwards, L.D.; Cho, M.H.; Anderson, W.H.; Coxson, H.O.; Lomas, D.A.; Silverman, E.K. Loci Identified by Genome-Wide Association Studies Influence Different Disease-Related Phenotypes in Chronic Obstructive Pulmonary Disease. Am. J. Respir. Crit. Care Med. 2010, 182, 1498-1505. [CrossRef]

19. Wilk, J.B.; Shrine, N.R.G.; Loehr, L.R.; Zhao, J.H.; Manichaikul, A.; Lopez, L.M.; Smith, A.V.; Heckbert, S.R.; Smolonska, J.; Tang, W.; et al. Genome-Wide Association Studies Identify CHRNA5/3 and HTR4 in the Development of Airflow Obstruction. Am. J. Respir. Crit. Care Med. 2012, 186, 622-632. [CrossRef]

20. Busch, R.; Hobbs, B.D.; Zhou, J.; Castaldi, P.J.; McGeachie, M.J.; Hardin, M.E.; Hawrylkiewicz, I.; Sliwinski, P.; Yim, J.-J.; Kim, W.J.; et al. Genetic Association and Risk Scores in a Chronic Obstructive Pulmonary Disease Meta-Analysis of 16,707 Subjects. Am. J. Respir. Cell Mol. Biol. 2017, 57, 35-46. [CrossRef]

21. Shrine, N.; Guyatt, A.L.; Erzurumluoglu, A.M.; Jackson, V.E.; Hobbs, B.D.; Melbourne, C.A.; Batini, C.; Fawcett, K.A.; Song, K.; Sakornsakolpat, P.; et al. New Genetic Signals for Lung Function Highlight Pathways and Chronic Obstructive Pulmonary Disease Associations across Multiple Ancestries. Nat. Genet. 2019, 51, 481-493. [CrossRef]

22. Diabasana, Z.; Perotin, J.-M.; Belgacemi, R.; Ancel, J.; Mulette, P.; Delepine, G.; Gosset, P.; Maskos, U.; Polette, M.; Deslée, G.; et al. Nicotinic Receptor Subunits Atlas in the Adult Human Lung. Int. J. Mol. Sci. 2020, 21, 7446. [CrossRef] [PubMed]

23. Bonini, M.; Usmani, O.S. The Role of the Small Airways in the Pathophysiology of Asthma and Chronic Obstructive Pulmonary Disease. Ther. Adv. Respir. Dis. 2015, 9, 281-293. [CrossRef] [PubMed]

24. Sciaccaluga, M.; Moriconi, C.; Martinello, K.; Catalano, M.; Bermudez, I.; Stitzel, J.A.; Maskos, U.; Fucile, S. Crucial Role of Nicotinic A5 Subunit Variants for $\mathrm{Ca}^{2+}$ Fluxes in Ventral Midbrain Neurons. FASEB J. 2015, 29, 3389-3398. [CrossRef] [PubMed]

25. Tammimäki, A.; Herder, P.; Li, P.; Esch, C.; Laughlin, J.R.; Akk, G.; Stitzel, J.A. Impact of Human D398N Single Nucleotide Polymorphism on Intracellular Calcium Response Mediated by A3 $\beta 4 \alpha 5$ Nicotinic Acetylcholine Receptors. Neuropharmacology 2012, 63, 1002-1011. [CrossRef] [PubMed]

26. George, A.A.; Lucero, L.M.; Damaj, M.I.; Lukas, R.J.; Chen, X.; Whiteaker, P. Function of Human A3ß4 $\alpha 5$ Nicotinic Acetylcholine Receptors Is Reduced by the A5(D398N) Variant. J. Biol. Chem. 2012, 287, 25151-25162. [CrossRef]

27. Adam, D.; Roux-Delrieu, J.; Luczka, E.; Bonnomet, A.; Lesage, J.; Mérol, J.-C.; Polette, M.; Abély, M.; Coraux, C. Cystic Fibrosis Airway Epithelium Remodelling: Involvement of Inflammation. J. Pathol. 2015, 235, 408-419. [CrossRef] [PubMed]

28. Jiang, D.; Schaefer, N.; Chu, H.W. Air-Liquid Interface Culture of Human and Mouse Airway Epithelial Cells. Methods Mol. Biol. 2018, 1809, 91-109. [CrossRef]

29. Schamberger, A.C.; Staab-Weijnitz, C.A.; Mise-Racek, N.; Eickelberg, O. Cigarette Smoke Alters Primary Human Bronchial Epithelial Cell Differentiation at the Air-Liquid Interface. Sci. Rep. 2015, 5, 8163. [CrossRef]

30. Müller, L.; Brighton, L.E.; Carson, J.L.; Fischer, W.A.; Jaspers, I. Culturing of Human Nasal Epithelial Cells at the Air Liquid Interface. J. Vis. Exp. 2013. [CrossRef]

31. Pezzulo, A.A.; Starner, T.D.; Scheetz, T.E.; Traver, G.L.; Tilley, A.E.; Harvey, B.-G.; Crystal, R.G.; McCray, P.B.; Zabner, J. The Air-Liquid Interface and Use of Primary Cell Cultures Are Important to Recapitulate the Transcriptional Profile of in Vivo Airway Epithelia. Am. J. Physiol. Lung Cell Mol. Physiol. 2011, 300, L25-L31. [CrossRef]

32. Ruiz García, S.; Deprez, M.; Lebrigand, K.; Cavard, A.; Paquet, A.; Arguel, M.-J.; Magnone, V.; Truchi, M.; Caballero, I.; Leroy, S.; et al. Novel Dynamics of Human Mucociliary Differentiation Revealed by Single-Cell RNA Sequencing of Nasal Epithelial Cultures. Development 2019. [CrossRef]

33. Perotin, J.-M.; Coraux, C.; Lagonotte, E.; Birembaut, P.; Delepine, G.; Polette, M.; Deslée, G.; Dormoy, V. Alteration of Primary Cilia in COPD. Eur. Respir. J. 2018, 52. [CrossRef]

34. Belgacemi, R.; Luczka, E.; Ancel, J.; Diabasana, Z.; Perotin, J.-M.; Germain, A.; Lalun, N.; Birembaut, P.; Dubernard, X.; Mérol, J.-C.; et al. Airway Epithelial Cell Differentiation Relies on Deficient Hedgehog Signalling in COPD. EBioMedicine 2020, 51, 102572. [CrossRef] 